
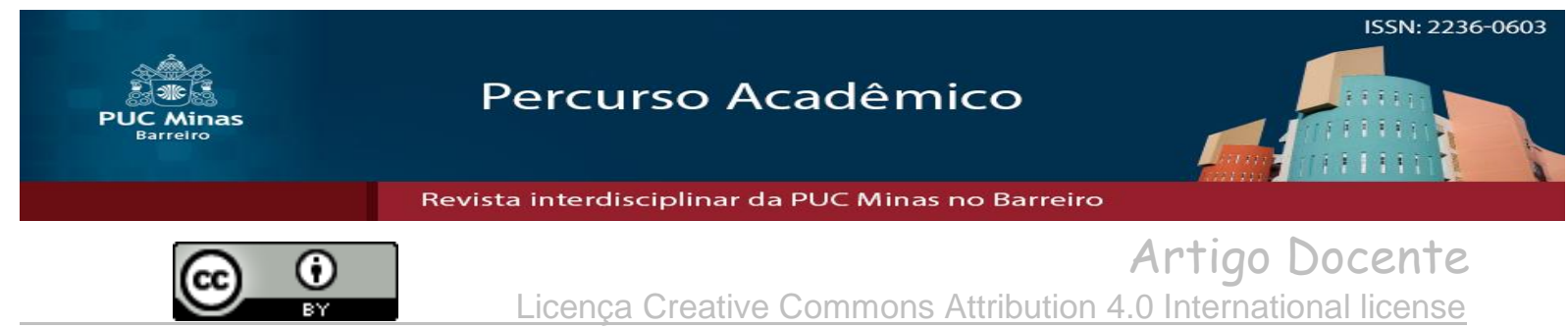

\title{
Considerações sobre a educação esclarecida e autônoma no pensamento de Theodor Adorno: implicações para o enfrentamento da violência escolar
}

\author{
Considerations on enlightened and autonomouseducation in \\ Theodor Adorno's thinking: implications for coping with school \\ violence
}

\author{
Ronaldo de Sousa Almeida ${ }^{1}$ \\ Ludmila de Almeida Freire ${ }^{2}$
}

\begin{abstract}
Resumo
Este artigo discute o relevante papel da educação no enfrentamento da violência na sociedade e, sobretudo, nas escolas. Encarada como uma das questões mais perturbadoras no âmbito escolar, a violência manifestada entre os estudantes tem sido amplamente discutida, na mediada em que se reconhece que os seus reflexos incidem negativamente na qualidade da educação, no rendimento dos alunos e na construção de uma cultura de paz. Uma vez que a escola não está separada do todo social, investigar a dimensão conflituosa e contraditória entre as relações sociais e educacionais, na forma como vêm se apresentando, é de fundamental importância para aprofundarmos nossa compreensão do fenômeno da violência na sociedade e seus reflexos na escola, bem como repensar o papel da educação. Nesse texto optamos por resgatar elementos de análise nos postulados de Theodor Adorno, sobretudo pelo fato de o filósofo destinar à educação um papel crucial diante desse desafio. Concluímos que a educação para a aquisição da autonomia e para a emancipação humana é um importante instrumento de mediação contra a violência e contra a barbárie, pois é capaz de proporcionar uma instigante reflexão nos indivíduos, sendo apropriada para fomentar processos de prevenção e/ou superação das condições internas e externas que operam a favor da violência.
\end{abstract}

Palavras-chave: Violência na escola. Educação para emancipação. Educação para autonomia.

\begin{abstract}
This article discusses the important role of education in tackling violence in society and, above all, in schools. Viewed as one of the most disturbing issues in the school environment, the violence manifested among students has been widely discussed, insofar as it is recognized that its impacts negatively affect the quality of education, student achievement and the construction of a culture of peace. Since the school is a part of the social whole, investigating the conflicting and contradictory dimension of social and educational relations, in the way they are presented, it is of fundamental importance to deepen our understanding of the phenomenon of violence in society and its impact on school, as well as rethinking the role of education. In this text we chose to rescue elements of analysis in the postulates of Theodor Adorno, especially because he assigns a crucial role to education in the face of this challenge. We conclude that education for the acquisition of autonomy and for human emancipation is an important instrument of mediation against violence and against barbarism, since it is capable of provoking reflection on individuals and is appropriate to foster processes of prevention and / or overcoming of the internal and external conditions that operate in favor of violence.
\end{abstract}

\footnotetext{
Artigo recebido em 10 de Novembro de 2016 e aprovado em 30 de Março de 2017.

${ }^{1}$ Doutor em Educação pela Universidade Federal do Ceará (UFC). Professor da Faculdade de Educação da

Universidade do Estado de Minas Gerais (UEMG). E-mail: ronaldoalmeidaufc@ gmail.com

${ }^{2}$ Doutora em Educação pela Universidade Federal do Ceará (UFC). Professora da Faculdade de Educação da Universidade do Estado de Minas Gerais (UEMG). E-mail: ludmilaalmeida82@ gmail.com
} 
Key-words: Violence in school. Education for emancipation. Education for autonomy.

Introdução

O fenômeno da violência nas instituições de ensino vem sendo encarado como uma das questões mais perturbadoras no âmbito escolar, cujos reflexos incidem negativamente na qualidade da educação, no rendimento dos estudantes e na construção de uma 'cultura de paz'. Uma vez que a escola não está separada do todo social, investigar a dimensão conflituosa e contraditória entre as relações sociais e educacionais, na forma como vêm se apresentando, é de fundamental importância para aprofundarmos nossa compreensão do fenômeno da violência na sociedade e seus reflexos na escola, bem como repensar o papel da educação. Nesse texto optamos por resgatar elementos de análise nos postulados de Theodor Adorno, sobretudo pelo fato de o filósofo destinar à educação um papel crucial diante desse desafio.

Corroborando com Adorno, enfatizamos a relevância da educação esclarecida e autônoma como mediação necessária para evitar e/ou superar a barbárie e suas manifestações na sociedade e na escola. Na obra Educação e Emancipação, o autor oferece destaque à educação esclarecida e autônoma como mediação necessária para evitar e/ou superar a violência, principalmente àquela na forma da barbárie.

A partir dessas análises, explicitamos alguns elementos da posição de Adorno sobre a ideia de que a educação e a escolarização precisam cumprir a sua tarefa emancipatória. E tal possibilidade só pode ocorrer se a educação adotar como princípio a capacidade de reflexão e de autodeterminação. Outro aspecto trazido no pensamento de Adorno diz respeito à resistência constante que a educação e o processo de escolarização devem manter contra a barbárie, explicitando e refletindo acerca dos motivos que levam à adoção da violência como mecanismo de resolução de conflitos.

O texto que apresentamos está organizado da seguinte forma: analisamos inicialmente o papel da educação para a contraviolência a partir de alguns pressupostos do autor acerca do trágico episódio do Nazismo. Em seguida, tomamos como fio condutor desta análise o papel inesgotável da educação contra o recrudescimento de atos atrozes, tanto no âmbito social, como no aspecto da educação formal, uma vez que a escola não está separa do todo social. Concluímos tecendo alguns apontamentos sobre as possibilidades do pensamento de Adorno no enfrentamento dessa problemática tão latente nos dias atuais. 


\section{Educação para a contraviolência}

Tendo como referência a sociedade alemã do período entre guerras e os acontecimentos desastrosos que se seguiram, Theodor Adorno, um dos estudiosos mais influentes da chamada Escola de Frankfurt $^{3}$, no seu livro Educação e Emancipação (1995), inicia um dos ensaios sugestivamente intitulado Educação após Auschwitz ${ }^{4}$, com a seguinte provocação "a exigência de que Auschwitz não se repita é primeira de todas para a educação". (ADORNO, 1995, p. 119). Destacando o imprescindível papel da educação para a contraviolência, o autor sinaliza que as condições que geraram a barbárie nazista poderiam ter sido evitadas por meio de uma educação emancipatória, ou seja, uma educação como mecanismo libertador do homem.

Adorno defende a libertação do indivíduo do processo de dominação da consciência - oriunda de uma sociedade administrada e afastada da reflexão moral - a partir de uma educação que caminhe na perspectiva da emancipação dos homens como possibilidade fundamental para sua ação plena no mundo. Tal educação deveria ser capaz de empoderar os homens e mulheres a agir, tendo como alicerce a capacidade de responder às questões conflitantes a partir do seu próprio esclarecimento, quer dizer, "a saída dos homens de sua auto-inculpável menoridade". (ADORNO, 1995, p. 169) ${ }^{5}$, tornando-se apto a participar e a questionar os pressupostos da sociedade vigente.

Quando trata da questão da agressão na forma de barbárie ou violência, o autor busca referência também em Freud, corroborando com o fato de que os indivíduos trazem consigo uma tendência não civilizada, que pode se manifestar quando encontra as condições favoráveis. Assim, a educação ganha uma relevância fundamental, pois é o meio para evitar que os homens sigam a tendência anticivilizatória, afastando-se da barbárie. A educação deve, portanto, ser direcionada à autoanálise e à autorreflexão,

\footnotetext{
${ }^{3}$ A Escola de Frankfurt consistia em um grupo de intelectuais que a partir de 1920 começou a produzir um pensamento conhecido como Teoria Crítica, voltado para a crítica da sociedade industrial avançada. Dentre os pensadores mais expoentes temos Theodor Adorno, Max Horkheimer, Herbert Marcuse e Walter Benjamim. Com a II Guerra Mundial (1939-1945), eles saíram de Frankfurt, na Alemanha, para se refugiar nos Estados Unidos, voltando apenas na década de 1950. Entre seus principais postulados estão as ideias: crítica da razão instrumental; indústria cultural; educação para emancipação.

${ }^{4}$ Auschwitz, construído em 1940 no sul da Polônia, foi o principal símbolo do extermínio da II Guerra Mundial por ser o maior dos campos de concentração nazista, construído em 1940.

${ }^{5}$ Importante frisar que Adorno vai tomar esse conceito de esclarecimento a partir do pensamento de Kant no seu ensaio "Resposta à pergunta o que é esclarecimento?".
} 
começando na infância, aspecto também sinalizado por Kant. Explicitando sua concepção de barbárie, Adorno (1995, p. 155, grifo nosso) esclarece:

\begin{abstract}
Entendo por barbárie algo muito simples, ou seja, que, estando na civilização do mais alto desenvolvimento tecnológico, as pessoas se encontrem atrasadas de um modo peculiarmente disforme em relação a sua própria civilização - e não apenas por não terem em sua arrasadora maioria experimentado a formação nos termos correspondentes ao conceito de civilização, mas também por se encontrarem tomadas por uma agressividade primitiva, um ódio primitivo, ou na terminologia culta, um impulso de destruição, que contribui ara aumentar ainda mais o perigo de que toda esta civilização venha a explodir, alias uma tendência imanente que a caracteriza. Considero tão urgente impedir isso que eu reordenaria todos os objetivos educacionais por esta prioridade.
\end{abstract}

Embora reconhecendo que a barbárie é uma possibilidade real no processo "civilizatório" da humanidade, e que especialmente na sociedade capitalista as condições político-sociais criam as bases para o desencadeamento de inúmeras situações e tipos de violências (pessoais e sociais), a educação se inscreve como ferramenta indispensável na condução de uma autopercepção crítica, desde a primeira infância, sendo uma de suas principais finalidades para a formação do caráter. Nesse sentido, Adorno (1995, p. 121-122) argumenta que:

A educação tem sentido unicamente como educação dirigida a auto reflexão crítica. Contudo, na medida em que, conforme os ensinamentos da psicologia profunda, todo caráter, inclusive daqueles que, mais tarde praticam crimes, forma-se na primeira infância, a educação que tem por objetivo evitar a repetição, precisa se encontrar na primeira infância.

Para o filósofo, a verdadeira educação é entendida como sinônimos de emancipação, esclarecimento e liberdade. Trata-se da necessidade de emancipação das condições impostas pela sociabilidade do capital, que imprime nos sujeitos o sentimento de adaptação e comodismo, fomentado também pelos mecanismos de uma indústria cultural. ${ }^{6} \mathrm{O}$ esclarecimento serviria como mecanismo necessário aos indivíduos para não aceitarem as exigências do processo de difusão da semicultura ${ }^{7}$ e as imposições da

\footnotetext{
${ }^{6} \mathrm{O}$ termo indústria cultural foi criado por Adorno e Horkheimer a fim de criticar e questionar a situação da arte e da cultura na sociedade atual. Ambos destacam que os aparelhos de reprodução e distribuição capitalistas da cultura estariam anulando aos poucos a arte erudita e popular, neutralizando a participação intelectual e criativa dos seus inventores e espectadores. Uma vez inserida na lógica da produção industrial, a cultura e a arte perderiam sua capacidade contestatória e crítica, anulando sua potência transformadora e reflexiva da vida.

${ }^{7} \mathrm{Na}$ acepção de Adorno e Horkheimer, sob as determinações da indústria cultural, a semicultura promove e alimenta a semiformação, tornando-se o modo de consciência dos indivíduos. As pessoas passam a consumir, ouvir, comprar, ler, sentir e até se orientar por ideias, anúncios e discursos difundidos pelos
} 
sociedade administrada. A liberdade de pensamento seria uma afirmação propositiva para uma ação consciente e questionadora frente à produção de uma cultura massificante.

Sem desconsiderar a dimensão psicológica presente na ação dos indivíduos, o autor tem a preocupação crucial com as análises referentes às condições que fomentam a barbárie e aponta para a educação como a mediação necessária para a superação da violência na busca pela emancipação. Adorno (1995, p. 159-160) define a barbárie da seguinte forma:

Suspeito que a barbárie existe em toda a parte em que há uma regressão à violência física primitiva, sem que haja uma vinculação transparente com objetivos racionais na sociedade, onde exista, portanto a identificação com a erupção da violência física. Por outro lado, em circunstâncias em que a violência conduz inclusive a situações bem constrangedoras em contextos transparentes para a geração de condições humanas mais dignas, a violência não pode sem mais nem menos ser condenada como barbárie.

É fato que o filósofo claramente relaciona o termo barbárie ao episódio do nazismo (e, por extensão, refere-se a qualquer ato que leve à degradação do humano), sendo este uma manifestação incontornável do mais atroz comportamento humano, possibilidade ainda presente e denunciada pelo autor como possível de repetição, uma vez que as chamas de Auschwitz não haviam sido completamente debeladas, fazendo referência a uma razão meramente instrumental que precisava ser revista. Durante o nazismo, a violência (física, simbólica e psicológica) parece ter sedimentado-se como normativa e ao mesmo tempo banal. Os cidadãos, defensores do regime, passaram a se identificar e a aceitá-la, mesmo estando aparentemente desvinculada de objetivos racionais.

Não resta dúvida de que, para Adorno, há situações de constrangimentos, conforme citação anterior, para que se "gere condições humanas mais dignas". Tratase aqui de uma luta justamente contra a violência na forma de exploração, de alienação, de semiformação, etc., tão presentes na sociedade capitalista.

meios de comunicação de massa. Tal movimento se dá, sobretudo, pela ausência de crítica e reflexão, acarretando adaptação e alienação. 


\title{
20 papel inesgotável da educação contra o recrudescimento de atos atrozes
}

Apesar de enfatizar o temor da possibilidade do retorno de projetos de dominação totalitários (a exemplo do Nazismo), cujas condições para sua volta não foram ainda refreadas, Adorno assevera que o papel da educação é impedir a manifestação da barbárie, destacando os dois aspectos: objetivo, no âmbito das relações sociais e produtivas; subjetivo, referente ao exercício das individualidades e singularidades dos sujeitos, quanto aos seus sentimentos e emoções. Nesse sentido, Zanolla (2010, p. 118), comentando o pensamento de Adorno, argumenta:

\begin{abstract}
Adorno conceitua e identifica o sentido da barbárie em dois aspectos: objetivo, referente aos fatores e situações sociais que contribuem para a violência no âmbito estrutural, da ordem das relações produtivas e, nos aspectos humanos inerentes à constituição da subjetividade, o que envolve reconhecer fatores que dizem respeito à dinâmica psíquica dos indivíduos, à 'sua alma', ou 'espírito', no sentido filosófico da singularidade humana: seus desejos, necessidades, sentimentos e emoções.
\end{abstract}

O retorno à barbárie que pode ocorrer a partir desses dois aspectos, de modo separado e/ou simultâneo, é uma possibilidade presente e é justamente por pensar assim que a preocupação de Adorno se centra na questão da educação para impedir e/ou superar a violência, principalmente na forma de barbárie. Se as possibilidades do retorno das condições perversas de violências persistem, a educação assume um papel importante no sentido de prevenir e impedir a sua manifestação.

Para Adorno, tanto a análise das condições objetivas como também das condições subjetivas são fundamentais para aguçar a reflexão sobre os fatos que conduziram a sociedade alemã à radicalidade empreendida na Segunda Guerra. Nesse sentido, Adorno (1995, p. 121) destaca:

É preciso buscar as raízes nos perseguidores e não nas vítimas, assassinadas sob os pretextos mais mesquinhos. Torna-se necessário o que a esse respeito uma vez denominei de inflexão em direção ao sujeito. É preciso reconhecer os mecanismos que tornam as pessoas capazes de cometer tais atos, é preciso revelar tais mecanismos a eles próprios, procurando impedir que se tornem novamente capazes de tais atos, na medida em que se desperta uma consciência geral acerca destes mecanismos [...]. Culpados são unicamente os que, desprovidos de consciência, voltaram contra aqueles seu ódio e sua fúria agressiva. É necessário contrapor-se a uma tal ausência de consciência, é preciso evitar que as pessoas golpeiem para os lados sem refletir a respeito de si próprias.

Ainda no ensaio Educação após Auschwitz, o autor sinaliza dois pontos fundamentais de ação da educação, a saber: a educação infantil atuando na formação do caráter; e o papel que a educação deve desempenhar na função de levar ao 
esclarecimento geral, que produz um clima intelectual, cultural e dos sujeitos. Nesse sentido, a educação possibilitaria uma constante reflexão para que não aconteçam tragédias e violências de modo consciente e/ou processos encarados como naturais. A referência é feita quando em momentos cruciais a ação da educação não se subtrai inteiramente à interferência dos indivíduos, mas como algo que a potencializa.

Nesse aspecto, há alusão a necessidade da formação moral na infância destacando-se o indispensável papel da educação para o desenvolvimento da consciência moral e para a aquisição do pensamento autônomo e reflexivo.

Outro aspecto tratado nos seus escritos diz respeito à questão da consciência coisificada. Para ele, alguns seres humanos chegaram a certo grau de frieza em todas as suas relações (isso sintetiza a ideia de mundo administrado, onde ciência e técnica estariam instrumentalizadas de forma absolutamente irracional, no sentido técnico e mecanicista), ao ponto de preferirem a companhia das máquinas em detrimento dos seres humanos e equipararem os próprios seres humanos a coisas.

Para Adorno (1995, p. 132), a técnica instrumentalizada tem um papel incisivo nessa coisificação da consciência, que considera a própria tecnologia como ente absoluto, fazendo os homens esquecer que são eles mesmos que produzem a tecnologia e não o contrário, como diz o nosso autor: "Os homens inclinam-se a considerar a técnica como sendo algo em si mesma, um fim em si mesmo, uma força própria, esquecendo que ele é a extensão dos braços do homem".

Adorno ainda ressalta, lembrando Auschwitz, o quanto é prejudicial a ação humana ser guiada cegamente pela autoridade, apartada de uma consciência moral.

\begin{abstract}
O que a psicologia denomina superego, a consciência moral, é substituído no contexto dos compromissos por autoridades exteriores, sem compromisso, intercambiáveis, como foi possível observar com muita nitidez também na Alemanha depois da queda do Terceiro Reich. Porém, justamente a disponibilidade em ficar do lado do poder, tomando exteriormente como norma curvar-se ao que é mais forte, constitui aquela índole dos algozes que nunca mais deve ressurgir. Por isto a recomendação dos compromissos é tão fatal. As pessoas que os assumem mais ou menos livremente são colocadas numa espécie de permanente estado de exceção de comando. O único poder efetivo contra o princípio de Auschwitz seria a autonomia, para usar expressão kantiana; o poder para a reflexão, a autodeterminação, a nãoparticipação. (ADORNO, 1995, p. 124-125).
\end{abstract}

Essa passagem de Adorno é um alerta para a sociedade e para os educadores. Alimenta a ideia de que é ainda possível buscar a práxis emancipatória por uma 
educação que não se renda diretamente ao sistema político-econômico, mas que tenha como foco primordial a formação crítico-reflexiva dos indivíduos. É fundamental refletir sobre o tipo de ser humano que nosso sistema social e educacional está erigindo. Somente a reflexão crítica e filosófica pode coibir atos atrozes e bárbaros, individuais e coletivos.

Em um dos diálogos radiofônicos, intitulado Educação - para quêe, o objetivo de Adorno não foi simplesmente mencionar a necessidade da educação, mas discutir a sua finalidade. Nesse sentido ele destaca que "a intenção não era para que fins a educação ainda seria necessária, mas sim: para onde a educação deve conduzir?”. (ADORNO, 1995, p. 139).

Tomando esse pensamento de Adorno, podemos dizer que é tarefa do educador consiste em repensar a realidade educacional; questionar as políticas educacionais impregnadas de ideologias impostas como corretas e intocáveis; discutir o sentido da formação e dos conteúdos ofertados; e possibilitar aos sujeitos do processo um olhar atento para as condições que exacerbam impulsos violentos. Quando a realidade educacional e cultural se torna mecânica e inflexível, apresenta-se em total descompasso com a sensibilidade do ser realmente humano. Questionando os papéis e as condições da família, da escola, da mídia, do sistema econômico, da política governamental, poderemos chegar a uma reflexão sobre as violências perpetradas na escola e sobre os fracassos educacionais, a fim de tomarmos decisões e ações para a minimização e/ou superação dos seus efeitos.

Adorno destaca como importância fundamental a tomada de consciência, enfatizando que cada acontecimento de violência, de barbárie, não se resume apenas ao ato da sua consumação, mas envolve outras questões que criaram a possibilidade para que a barbárie viesse a acontecer! Ao final do ensaio Educação após Auschwitz, Adorno aborda os assassinos de gabinete, segundo ele:

Temo que será difícil evitar o aparecimento de assassinos de gabinete, por
mais abrangentes que sejam as medidas educacionais. Mas que haja pessoas
que, em posições subalternas, enquanto serviçais, façam coisas que
perpetuam sua própria servidão, tornando-as indigna; que continue a haver
Boger e Kaduks, contra isto é possível empreender algo mediante a educação
e o esclarecimento. (ADORNO, 1995, p.123).

Apesar de não ser possível afirmar que a educação será capaz de garantir o não retorno da barbárie, ela deverá cumprir um papel inesgotável contra o recrudescimento 
de atos atrozes, cujas marcas profundas deixadas na história não desaparecerão. Para o pensador frankfurtiano, a educação, desde a tenra idade, deveria criar um clima cultural, espiritual e social para que não permita a repetição de atos semelhantes àqueles vivenciados em Auschwitz.

\section{À guisa de conclusão}

A educação só poderá contribuir para o esclarecimento, emancipação e autonomia dos indivíduos se adotar como princípio a capacidade de reflexão e de autodeterminação. Outro aspecto diz respeito à obstinação constante contra a barbárie, explicitando e refletindo acerca dos motivos que levaram àquela violência (e a outros tipos) com tamanha amplitude, registradas na história, reconhecendo que as condições que as possibilitaram ainda estão vivas.

Todavia, se a educação estiver tão somente a serviço do mundo administrado, perderá certamente sua dimensão emancipatória e potência libertadora. Adorno enfatiza a escolha da via real, talvez a única possível: a educação deve ser crítica e autocrítica. Todo o empenho do educador deve concentrar-se na formação democrática do cidadão responsável.

A exigência defendida por Adorno reacende uma discussão oportuna na contemporaneidade. Volta ao centro do debate o papel desempenhado pelas instituições de ensino formais, no desafio de desenvolver uma educação para a maioridade e autonomia. Estariam as escolas hoje cumprido essa tarefa? Em que medida a educação e a escola contemporânea tem conseguido limitar, evitar e/ou superar a ação de comportamentos violentos entre os adolescentes e jovens? Que compreensão se tem do fenômeno da violência hoje e das suas diferentes manifestações, em especial no âmbito escolar? Que ações vêm sendo adotadas para a construção da cultura da contraviolência numa perspectiva crítica e reflexiva?

Com base nesses questionamentos, a educação para a aquisição da consciência moral, para o esclarecimento, para a autonomia, e para a emancipação humana é um importante instrumento de mediação contra a violência e contra a barbárie, pois é capaz de proporcionar uma instigante reflexão nos indivíduos, sendo apropriada para fomentar processos de prevenção e/ou superação das condições internas e externas que operam a favor da violência 


\section{REFERÊNCIAS}

ADORNO, Theodor W. Educação e emancipação. Tradução de Wolfgang Leo Maar. Rio de Janeiro: Paz e Terra, 1995.

ADORNO, Theodor W. Educação após Auschwitz. In: Educação e Emancipação. Rio de Janeiro: Paz e Terra, 1995. p. 119-138.

ADORNO, Theodor W. Educação - para quê? In: Educação e Emancipação. Rio de Janeiro: Paz e Terra. 1995. p. 139-154

KANT, Immanuel. Resposta à pergunta: Que é "Esclarecimento"? (Aufklärung). In: Textos Seletos. Trad. Floriano de Sousa Fernandes. 3. ed. Petrópolis: Editora Vozes, 2005.

ZANOLLA, Sílvia Rosa. Educação e barbárie: aspectos culturais da violência na perspectiva da teoria crítica da sociedade. Sociedade e Cultura, Goiânia, v. 13, n. 1, p. 117-123, jan./jun. 2010. 